\title{
Suppression of Th17 response by Streptococcus thermophilus ST28 through induction of IFN- $\gamma$
}

\author{
TASUKU OGITA $^{1}$, YUSUKE TANII ${ }^{1}$, HIDETOSHI MORITA $^{2}$, TAKUYA SUZUKI $^{1}$ and SOICHI TANABE $^{1}$ \\ ${ }^{1}$ Graduate School of Biosphere Science, Hiroshima University, Higashi-Hiroshima 739-8528; \\ ${ }^{2}$ School of Veterinary Medicine, Azabu University, Chuo, Sagamihara, Kanagawa 252-5201, Japan
}

Received May 12, 2011; Accepted June 17, 2011

DOI: 10.3892/ijmm.2011.755

\begin{abstract}
The proinflammatory cytokine interleukin (IL)-17 plays important roles in various inflammatory diseases, and IL-17-producing T helper 17 cells (Th17) have received much attention. For therapy of Th17-mediated diseases, some reports have indicated the clinical efficacy of lactic acid bacteria, including Streptococcus thermophilus. In this study, we examined the mechanism for the suppressive effects of $S$. thermophilus ST28 on the Th17 response in murine splenocytes stimulated with transforming growth factor (TGF)- $\beta$ plus IL-6. Stimulation with TGF- $\beta$ plus IL- 6 increased mRNA expression of IL-17 and its production in the splenocytes, but ST28 markedly suppressed both. Meanwhile, ST28 increased the mRNA expression of interferon (IFN)- $\gamma$ as well as its production. AntiIFN- $\gamma$ completely cancelled the suppressive effect of ST28 on IL-17 production. From these data, it was concluded that IFN- $\gamma$ induced by ST28 had an important role on the effect. A genomic DNA $(10 \mu \mathrm{g} / \mathrm{ml})$ from ST28 effectively suppressed IL-17 production, probably via the Toll-like receptor 9. Therefore, modulation of Th1/Th17 balance would be one of the mechanisms under which $S$. thermophilus ST28 exerts an anti-inflammatory effect.
\end{abstract}

\section{Introduction}

The beneficial effects of probiotics have been recognized for a long time (1). Over the last decade, several studies have proven the preventive and curative features of these bacteria against some immune diseases. Bacterial constituents such as peptidoglycans, lipoteichoic acid (LTA) and bacterial DNA can modulate immune responses $(2,3)$. Our group has also reported that LTA enforces the intestinal barrier function via Toll-like receptor (TLR)2 signaling $(4,5)$. There is growing evidence to suggest that probiotic bacteria may have, in straindependent manner, a potential use as anti-inflammatory agents

Correspondence to: Dr Soichi Tanabe, Graduate School of Biosphere Science, Hiroshima University, 1-4-4 Kagamiyama, Higashi-Hiroshima 739-8528, Japan

E-mail: stanabe@hiroshima-u.ac.jp

Key words: Streptococcus thermophilus, interleukin-17, T helper 17 cells in some chronic inflammatory diseases such as inflammatory bowel disease (IBD) (6,7).

Recently, T helper 17 cells (Th17) have received considerable attention, because they produce a pleiotropic cytokine, interleukin (IL)-17, and exhibit effector functions distinct from other T cells (8-10). Pathogens such as Klebsiella pneumoniae, Mycobacterium tuberculosis and Candida albicans can trigger a strong Th17 response (10), and the primary function of Th17 is the clearance of pathogens. IL-17 also up-regulates expression of anti-microbial molecules such as $\beta$-defensins $(9,11)$.

However, IL-17 is not always beneficial in protecting the host from bacterial infection. Indeed, IL-17 induces tissue inflammation potently and has been associated with the pathogenesis of many experimental autoimmune diseases and human inflammatory conditions (10). For example, Th17 are related to IBD (12), rheumatoid arthritis (13) and asthma (14).

Interestingly, it was reported that colonization of mouse small intestine with a single commensal microbe, segmented filamentous bacterium, induces Th17 in the lamina propria (15). At steady state, Th17 cells are abundant in small intestinal lamina propria, and it is of significance that intestinal commensal microbes can contribute to Th17-mediated mucosal protection (15). However, the involvement of probiotics and/or starters of fermented foods in Th17-skewed conditions is still unclear.

Recently, we have found that heat-killed Bifidobacterium longum subsp. infantis JCM 1222 (type strain) suppresses IL-17 production both in murine splenocytes and colon organ culture (16). The precise mechanisms for the suppressive effect have not been fully clarified. Compared to bifidobacteria, S. thermophilus is more frequently used as a yogurt starter, and we can easily consume it in our daily life. Here we report that, in a Th17-skewed condition, heat-killed S. thermophilus ST28 suppressed IL-17 production in murine splenocytes through induction of interferon (IFN) $\gamma$ and modulation of the balance between Th1 and Th17. IL-17 production in the splenocytes was also shown to be inhibited by a genomic DNA from ST28.

\section{Materials and methods}

Reagents. RPMI-1640 medium, penicillin and streptomycin were purchased from Life Technologies (Foster City, CA, USA). Fetal bovine serum (FBS) was obtained from ICN Biomedicals (Osaka, Japan). Recombinant human transforming 
growth factor (TGF)- $\beta$, mouse IL- 6 and mouse IFN- $\gamma$ were obtained from R\&D Systems (Minneapolis, MN, USA). MRS and M17 broth were both purchased from Merck (Darmstadt, Germany), and GAM broth was purchased from Nissui Pharmaceutical (Tokyo, Japan). Cytosine guanine dinucleotide $(\mathrm{CpG})$ oligonucleotide (ODN 2006, phosphorothioated 5'-TCGTCGTTTTGTCGTTTTGTCGTT-3') (17) was obtained from Nihon Gene Research Laboratories (Miyagi, Japan) and used as a TLR9 ligand. (S)-[2,3-bis(palmitoyloxy)-(2-RS)propyl]-N-palmitoyl-(R)-Cys-(S)-Ser-(S)-Lys 4 -OH (PCSK) was purchased from Calbiochem (San Diego, CA, USA) and used as a TLR2 ligand. All other chemicals were of reagent grade.

Bacterial cultures. S. thermophilus ST28, which was isolated from raw cow's milk in Tochigi, Japan, and, B. longum GLC6 were obtained from a bacterial library (property of Glico Dairy Products, Japan). ST28 was cultured in MRS broth and cultures were incubated in M17 broth at $37^{\circ} \mathrm{C}$ for $17-65 \mathrm{~h}$. GLC6 was cultured in GAM broth and cultures were incubated at $37^{\circ} \mathrm{C}$ for $18 \mathrm{~h}$ under anaerobic condition (AnaeroPack, Mitsubishi Gas Chemical, Tokyo, Japan). The bacterial cell suspensions were washed with distilled water, incubated at $100^{\circ} \mathrm{C}$ for $50 \mathrm{~min}$ (16) and then lyophilized. Subsequently, heat-killed bacteria were added to the murine splenocyte as described below.

Murine splenocyte culture. Six-week-old female Balb/c mice were obtained from Charles River (Kanagawa, Japan), and they were sacrificed by cervical dislocation. The spleen was removed, and splenocytes $\left(1.2 \times 10^{6}\right.$ cells $)$ were incubated with $2 \mathrm{ng} / \mathrm{ml} \mathrm{TGF}-\beta$ plus $20 \mathrm{ng} / \mathrm{ml} \mathrm{IL-} 6$ at $37^{\circ} \mathrm{C}$ for $72 \mathrm{~h}$ in $120 \mu \mathrm{l}$ of RPMI-1640 medium supplemented with $10 \%$ FBS, $10 \mu \mathrm{M}$ 2-mercaptoethanol, $10 \mathrm{mM}$ HEPES, penicillin, and streptomycin in a 96-well cell culture plate (Thermo Fisher Scientific, Waltham, MA, USA). Heat-killed ST28 (1.2x106 cells) were added to the culture. A culture in which no TGF- $\beta$ plus IL- 6 or heat-killed bacterial cells were added was included as a control. The institutional guidelines for the care and use of animals were followed, and all animal experimental procedures were approved by Hiroshima University (no. D08-15).

mRNA expression analyses. After culturing, the plate was centrifuged and RNA was extracted from cells using TRIzol (Life Technologies). The reverse-transcription (RT) reaction was performed with the high-capacity cDNA reverse transcription kit (Life Technologies) at $25^{\circ} \mathrm{C}$ for $10 \mathrm{~min}$ and at $37^{\circ} \mathrm{C}$ for $120 \mathrm{~min}$. The reaction was terminated by heating at $85^{\circ} \mathrm{C}$ for $5 \mathrm{~min}$ followed by cooling at $4^{\circ} \mathrm{C}$. Real-time PCR was performed using the KAPA SYBR FAST ABI PRISM qPCR kit (Kapa Biosystems, Woburn, MA, USA). Primers were designed using the Primer 3 plus program (18). Primer sequences are shown in Table I. The reaction was performed at $95^{\circ} \mathrm{C}$ for $2 \mathrm{~min}$, followed by 40 cycles of $95^{\circ} \mathrm{C}$ for $5 \mathrm{sec}$ and $60^{\circ} \mathrm{C}$ for $30 \mathrm{sec}$. The dissociation stage was analyzed at $95^{\circ} \mathrm{C}$ for $15 \mathrm{sec}$, followed by 1 cycle of $60^{\circ} \mathrm{C}$ for $15 \mathrm{sec}$ and $95^{\circ} \mathrm{C}$ for $15 \mathrm{sec}$. The fluorescence of the SYBR-Green dye was determined as a function of the PCR cycle number, giving the threshold cycle number at which amplification reached a significant threshold. Data were analyzed by the $\Delta \Delta \mathrm{Ct}$ method and presented as fold changes in gene expression from the non-stimulation level, after normalization to the $\beta$-actin gene.
Table I. Primer sequences used in this study.

\begin{tabular}{|c|c|}
\hline Gene & Sequence \\
\hline \multirow[t]{2}{*}{$R O R \gamma t$} & Forward 5'-GCAAATACGGTGGTGTGGA-3' \\
\hline & Reverse 5'-CGCTGAGGAAGTGGGAAA-3' \\
\hline \multirow[t]{2}{*}{$I L-17 \alpha$} & Forward 5'-TGGATTCAGAGGCAGATTCA-3' \\
\hline & Reverse 5'-CAGTTTGGGACCCCTTTACA-3' \\
\hline \multirow[t]{2}{*}{$I F N-\gamma$} & Forward 5'-TATCTGGAGGAACTGGCAAA-3' \\
\hline & Reverse 5'-TGACGCTTATGTTGTTGCTG-3' \\
\hline \multirow[t]{2}{*}{ T-bet } & Forward 5'-ACCAGAACGCAGAGATCACTCA-3' \\
\hline & Reverse 5'-CAAAGTTCTCCCGGAATCCTT-3' \\
\hline \multirow[t]{2}{*}{$\beta$-actin } & Forward 5'-TCATGAAGTGTGACGTGGACATC-3' \\
\hline & Reverse 5'-TGCATCCTGTCGGCAATG-3' \\
\hline
\end{tabular}

Culture supernatants were assayed for IFN- $\gamma$ concentration by sandwich ELISA (DuoSet, R\&D Systems) according to the manufacturer's instructions (Fig. 1C).

The effects of IFN- $\gamma$ and TLR9 ligand on Th17 suppression. To examine the roles of IFN- $\gamma$ and IL-10 in the inhibition of IL-17 production, anti-IFN- $\gamma$ (clone: XMG1.2, Endogen, Cambridge, MA, USA) and anti-IL-10 (clone: JES052A5, R\&D Systems) antibodies were added to the previously described culture medium at a concentration of $10 \mu \mathrm{g} / \mathrm{ml}$ (Fig. 2). After culturing, the plate was centrifuged and culture supernatants were assayed for IL-17 (IL-17A) concentration by sandwich ELISA (DuoSet, R\&D Systems) according to the manufacturer's instructions. As necessary, splenocytes were stimulated with $2 \mathrm{ng} / \mathrm{ml}$ TGF- $\beta$ plus $20 \mathrm{ng} / \mathrm{ml}$ IL- 6 in the presence of $1 \mathrm{ng} / \mathrm{ml} \mathrm{IFN}-\gamma$ (Fig. 2) or 1 or $10 \mu \mathrm{g} / \mathrm{ml} \mathrm{CpG} \mathrm{oligonucleotide}$ or PCSK (Fig. 4), in the place of ST28.

Separately, genomic DNAs from ST28 and GLC6 were prepared based on the method of Luchansky et al (19) with some modifications. Briefly, bacterial cells were treated with $0.1 \mathrm{mg} / \mathrm{ml}$ mutanolysin (Sigma-Aldrich) in TE buffer $(10 \mathrm{mM}$ Tris-HCl, $1 \mathrm{mM}$ EDTA, $\mathrm{pH}$ 8.0) for $1 \mathrm{~h}$ at $37^{\circ} \mathrm{C}$, and then with $0.5 \mathrm{~g} / \mathrm{ml}$ lysozyme (Wako Pure Chemicals, Osaka, Japan) for $1 \mathrm{~h}$ at $37^{\circ} \mathrm{C}$. After centrifugation, the precipitated bacterial cells were incubated with $1.25 \%$ SDS in TE buffer containing Tween-20 (Kanto Chemicals, Tokyo, Japan) overnight at $37^{\circ} \mathrm{C}$. The obtained DNA was recovered by the phenol-chloroform method. Splenocytes were stimulated with $2 \mathrm{ng} / \mathrm{ml}$ TGF- $\beta$ plus $20 \mathrm{ng} / \mathrm{ml} \mathrm{IL-6}$ in the presence of this DNA (1 or $10 \mu \mathrm{g} / \mathrm{ml})$ (Fig. 3).

Statistical analysis. Statistical analysis was performed using one-way ANOVA followed by the Tukey's post-hoc test.

\section{Results}

S. thermophilus ST28 induces differentiation towards Thl and subsequently suppresses Th17. Murine splenocytes were stimulated by TGF- $\beta$ plus IL- 6 to skew towards a Th17 condition and to induce IL-17 production (20). The mRNA expression changes of ROR- $\gamma$ t and T-bet, as well as IL-17 and IFN- $\gamma$, by the addition of ST28, were measured. Although the mRNAs of 
A

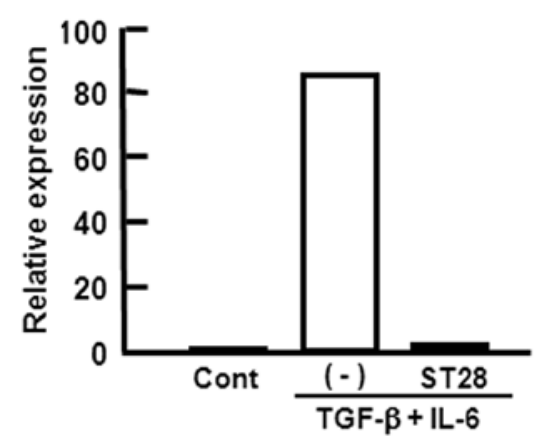

B

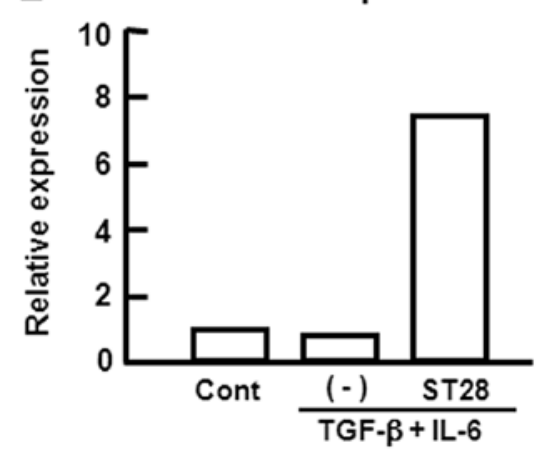

RORYt

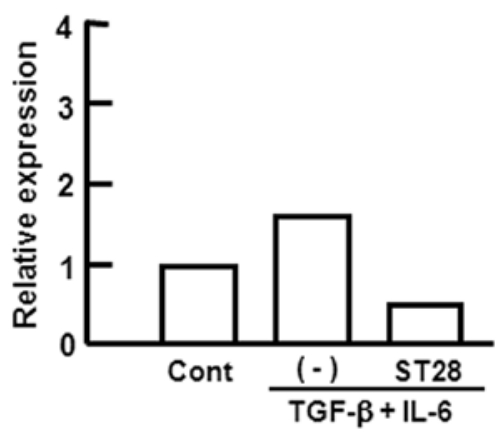

T-bet

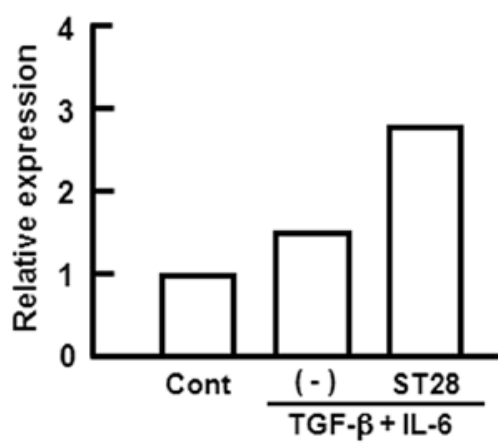

C

IFN-Y

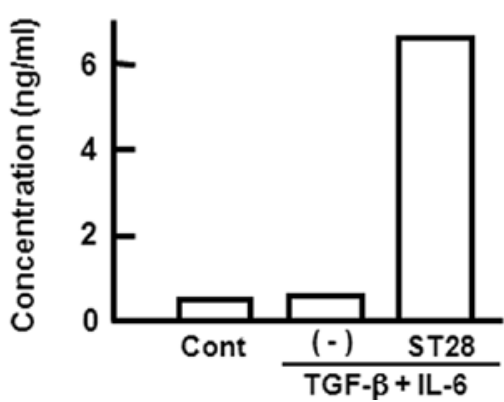

Figure 1. Effects of S. thermophilus ST28 on mRNA expression of Th17- and Th1-related genes and IFN- $\gamma$ production in murine splenocytes. Splenocytes were stimulated with TGF- $\beta$ plus IL- 6 for $72 \mathrm{~h}$ at $37^{\circ} \mathrm{C}$ in the presence or absence of ST 28 . After culturing, RNA was extracted from cells and the mRNA expression was examined by real-time RT-PCR (A and B). Data were analyzed by the $\Delta \Delta \mathrm{Ct}$ method and presented as the fold change in gene expression from the nonstimulation level, after normalization to the $\beta$-actin gene. Data are representative of one of three independent experiments. Separately, culture supernatants were harvested and assayed for IFN- $\gamma$ concentration by sandwich ELISA (C).

both IL-17 and ROR- $\gamma$ t were up-regulated by stimulation with TGF- $\beta$ plus IL-6, ST2 8 completely inhibited both expressions (Fig. 1A). Simultaneously, the mRNA expression of IFN- $\gamma$ and T-bet was induced by ST28 (Fig. 1B). In addition, IFN- $\gamma$ production in the stimulated splenocytes was strongly induced by ST28 (Fig. 1C). It was revealed that ST28-induced Th1 cell development from naïve $\mathrm{T}$ cells.

To clarify the correlation between Th1 induction and Th17 inhibition by ST28, we incubated splenocytes with ST28 under stimulation with TGF- $\beta$ plus IL- 6 in the presence or absence of anti-IFN- $\gamma$ antibody to measure neutralization. As expected, anti-IFN- $\gamma$ antibody completely cancelled the suppressive effect of ST28 (Fig. 2A). Instead of ST28, we incubated stimulated splenocytes with authentic IFN- $\gamma$. IFN- $\gamma$ similarly suppressed IL-17 production in stimulated splenocytes (Fig. 2A), while the anti-IL-10 antibody failed to abolish this suppressive effect (Fig. 2B). From this data, we conclude that Th1, but not regulatory T cells (Treg), antagonized Th17 in a Th17-skewed condition.

ST28 genomic DNA suppresses $I L-17$ production. To identify what kind of molecule in ST28 suppressed IL-17 production, the involvement of genomic DNA was assessed. ST28 genomic DNA, but not B. longum GLC6 genomic DNA, significantly suppressed IL-17 production in stimulated splenocytes (Fig. 3). This data indicated that ST28 suppressed IL-17 production in a genomic sequence-dependent manner.

In general, microbial DNA is recognized by a patternrecognition receptor such as TLR9 (21). To clarify the involvement of TLR9 in the suppression of IL-17 production, we incubated stimulated splenocytes with the $\mathrm{CpG}$ oligonucleotide (ODN 2006) (17). PCSK, a TLR2 synthetic ligand, 
A

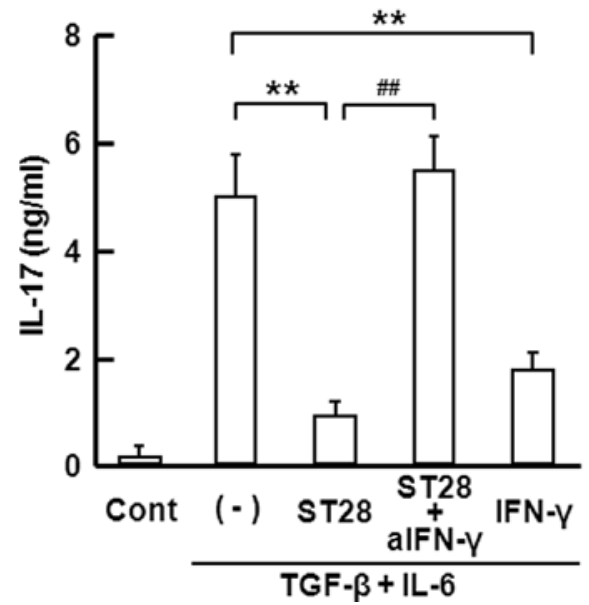

B

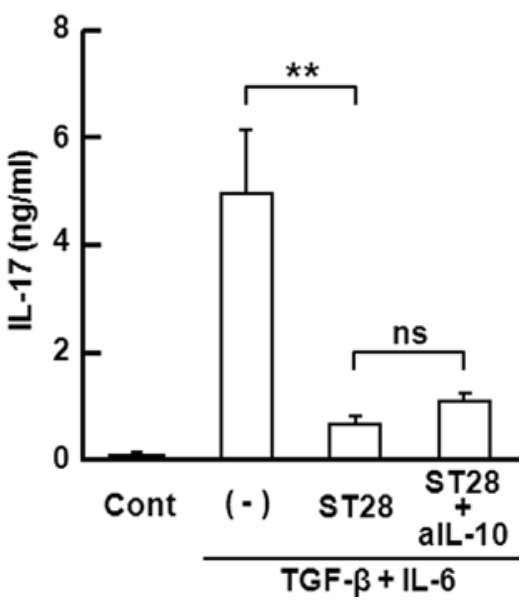

Figure 2. Effects of anti-IFN- $\gamma$ and anti-IL-10 antibodies on the suppressive effects of ST28 on IL-17 production. Stimulated splenocytes were incubated with ST28 in the presence or absence of anti-IFN- $\gamma$ (A) or anti-IL-10 (B) antibodies as neutralizing antibodies, or with authentic IFN- $\gamma$ (1 ng/ml) instead of ST28. Culture supernatants were harvested and assayed for IL-17 concentration $(\mathrm{n}=3)$. ${ }^{* *} \mathrm{P}<0.01$ in comparison with TGF- $\beta$ plus IL-6 (-); ${ }^{\# \#} \mathrm{P}<0.01$ in comparison with ST28. ns, not significant.

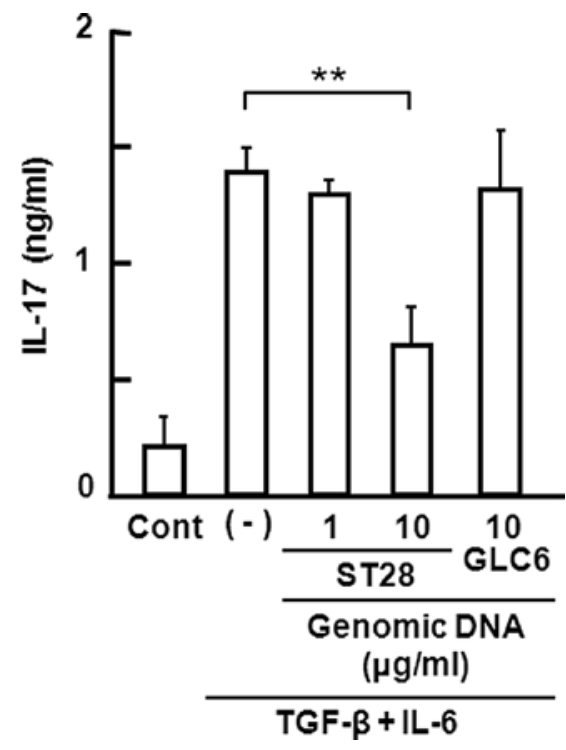

Figure 3. Effects of a genomic DNA from ST28 on IL-17 production in murine splenocytes. Splenocytes were incubated with TGF- $\beta$ plus IL- 6 for $72 \mathrm{~h}$ at $37^{\circ} \mathrm{C}$ in the presence or absence of a genomic DNA from $S$. thermophilus ST28 $(1$ or $10 \mu \mathrm{g} / \mathrm{ml})$ or B. longum GLC6 $(10 \mu \mathrm{g} / \mathrm{ml})$. Culture supernatants were harvested and assayed for IL-17 concentration $(n=3)$. ${ }^{* *} \mathrm{P}<0.01$ in comparison with TGF- $\beta$ plus IL-6 (-).

was also evaluated for its suppressive activity. Since PCSK did not suppress IL-17 production in splenocytes, it was assumed that the TLR2 ligand in ST28 alone could not suppress IL-17 production in murine splenocytes. By contrast, ODN2006 significantly suppressed IL-17 production in splenocytes (Fig. 4). Taken together with Fig. 3, we concluded that one of the components in ST28 with Th17-suppressive activity was its genomic DNA.

\section{Discussion}

Classically, $\mathrm{CD}^{+}$helper $\mathrm{T}$ cells are divided into two major subsets, Th1 induced by IL-12 and Th2 induced by IL-4 (8).
IFN- $\gamma$ is the signature cytokine of Th1, and IL-4 and -5 are the defining cytokines of Th2. Th1 drives cell-mediated immune responses leading to tissue damage, whereas, Th2 drives certain antibody-mediated responses, particularly those that are involved in allergy dominated by $\operatorname{IgE}$. However, several studies show contradictory features of IFN- $\gamma$. For example, administration of IFN- $\gamma$ itself ameliorated paralysis in experimental allergic encephalomyelitis, while antibodies to IFN- $\gamma$ exacerbated encephalomyelitis (22). Afterwards, the novel subset Th17, distinct from Th1 and Th2, was identified and solved this contradiction. It is currently well established that Th17 has a great role in tissue inflammation $(8-10,23)$. Also, the relationship between Th17 and commensal bacteria is now extensively studied in the aspect of immunomodulation $(15,24,25)$. Some probiotics are reported to be beneficial for IBD $(6,7)$, one of the Th17-related diseases. However, the involvement of the probiotics in Th17-skewed conditions is still unclear.

Although recent studies suggest that Th1 and Th17 both govern inflammation $(26,27)$, we clearly demonstrated in this study that $S$. thermophilus ST28 suppressed IL-17 production by Th17 in murine splenocytes by induction of inclined differentiation towards Th1 (Fig. 1B). The differentiation towards Th1 by ST28 was supported by the up-regulation of T-bet (Fig. 1B). More noteworthy are that the anti-IFN- $\gamma$ antibody completely cancelled the suppressive effect of ST28 and that IFN- $\gamma$ alone suppressed IL-17 production in stimulated splenocytes (Fig. 2A). Therefore, it is highly probable that, Th1 and Th17 are antagonistic towards each other and ST28 controls the balance of Th1/Th17, at least in a Th17-skewed condition. Interestingly, IFN- $\gamma$ exerts a biphasic effect. For example, blocking IFN- $\gamma$ at the early stages after immunization with type II collagen resulted in decreased anti-collagen antibody levels and severity of arthritis, whereas late treatment had aggravating effects and these effects were mirrored by IFN- $\gamma$ treatment (28). Furthermore, several recent studies have clearly demonstrated differential roles of Th1 and Th17 in tissue inflammation (29). More detailed research is necessary to clarify the multiple roles of IFN- $\gamma$ in inflammatory conditions. 
A

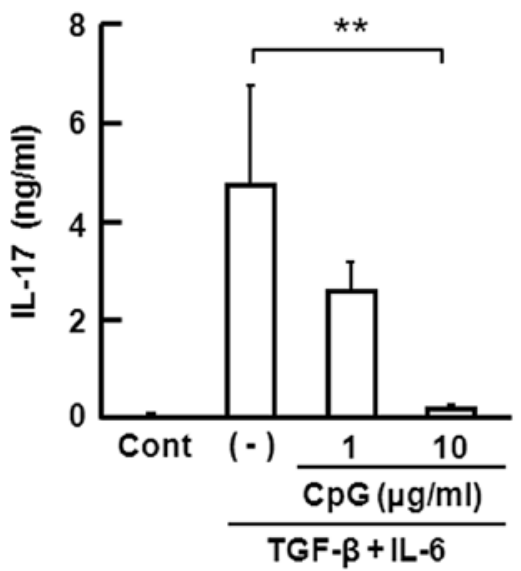

B

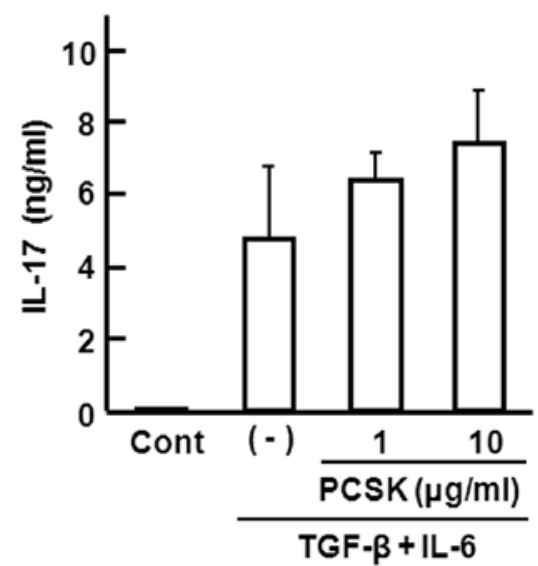

Figure 4. Effects of a CpG oligonucleotide (A) and PCSK (B) on IL-17 production in murine splenocytes. Splenocytes were incubated with TGF- $\beta$ plus IL-6 for $72 \mathrm{~h}$ at $37^{\circ} \mathrm{C}$ in the presence or absence of a CpG oligonucleotide or PCSK (1 or $\left.10 \mu \mathrm{g} / \mathrm{ml}\right)$. Culture supernatants were harvested and assayed for IL-17 concentration $(n=3) .{ }^{* *} \mathrm{P}<0.01$ in comparison with TGF- $\beta$ plus IL-6 (-).

In order to induce differentiation towards Th1, phagocytosis of ST28 by antigen-presenting cells such as dendritic cells (DCs) in splenocytes and subsequent stimulation of DCs to induce IL-12 would be necessary. In this regard, ST28 might trigger stimulation of DCs in splenocytes effectively. At the substance level, genomic DNA of ST28 was found to possess IL-17 suppressive activity (Fig. 3). Several studies showed that TLR9 signaling had an important role for modulating experimental allergic encephalomyelitis and colitis. It was reported that TLR9 ligands mediated the anti-inflammatory effects of probiotics in murine experimental colitis (30). Since Th17 is deeply involved in these symptoms, we postulated that TLR9 ligands directly inhibit Th17 response. CpG oligonucleotide (ODN 2006) as a representative TLR9 ligand suppressed IL-17 production in splenocytes (Fig. 4A). Generally, CpG oligonucleotide is an extremely potent stimulator of DCs and macrophages and causes the induction of Th1 response (31). Taken together, it was suggested that ST28-induced Th1 response and suppressed IL-17 production via TLR9.

Clinical efficacy of probiotic bacteria in ulcerative colitis, a form of IBD, has been investigated in several studies, and formulations such as VSL\#3 (Sigma-Tau Pharmaceuticals, Gaithersburg, MD, USA), Escherichia coli Nissle 1917 and L. rhamnosus GG have been studied extensively (32). VSL\#3 is a mixture containing $S$. thermophilus, four lactobacilli (L. plantarum, L. acidophilus, L. casei and L. delbrueckii subsp. bulgaricus) and three bifidobacteria (B. longum subsp. longum, B. longum subsp. infantis and B. breve). Multiple mechanisms of action have been suggested to explain the protective effects of VSL\#3 in intestinal inflammation. Most recently, it was reported that VSL\#3 stimulated, rather than suppressed, epithelial innate immune responses, i.e. increased production of epithelium-derived TNF- $\alpha$ (33). Our results could also be potentially important from a clinical point of view, since they present a novel anti-inflammatory mechanism of $S$.thermophilus, that is, suppression of Th17 by induction of IFN- $\gamma$. Indeed, a number of studies have shown that $S$. thermophilus promotes production of Th1-skewing cytokines such as IL-12 and IFN- $\gamma$ (34). It is also interesting to assess whether IL-17 levels would decrease in convalescence tissue in patients administered S. thermophilus.

In conclusion, this is the first study to show that $S$. thermophilus ST28 suppressed IL-17 production in Th17 in murine splenocytes via controlling the balance of Th1/Th17. Since S. thermophilus has a long history of being safely consumed and a good starter for yogurt, its further application to the amelioration of Th17-mediated diseases such as IBD is expected to be beneficial.

\section{Acknowledgements}

This research was partially supported by the Japanese Ministry of Education, Science, Sports and Culture Grant-in-Aid for S. T. We would like to thank Ms. Megumi Nakashima (Hiroshima University) for her technical assistance in our laboratory. We also thank Glico Dairy Products (Tokyo, Japan) for providing us S. thermophilus ST28 and B. longum GLC6 from their bacterial library.

\section{References}

1. Goldin BR: Probiotics and health: from history to future. In Probiotics and Health Claims. Kneifel W and Salminen S (eds). Blackwell Publishing Ltd., New Jersey, pp1-16, 2011.

2. Grangette C, Nutten S, Palumbo E, et al: Enhanced anti-inflammatory capacity of Lactobacillus plantarum mutant synthesizing modified teichoic acids. Proc Natl Acad Sci USA 102: 10321-10326, 2005.

3. Gómez-Llorente C, Muñoz S and Gil A: Role of toll-like receptors in the development of immunotolerance mediated by probiotics. Proc Nutr Soc 69: 381-389, 2010.

4. Miyauchi E, Morita H, Okuda J, et al: Cell wall fraction of Enterococcus hirae ameliorates TNF- $\alpha$-induced barrier impairment in the human epithelial barrier function. Lett Appl Microbiol 46: 469-476, 2008

5. Miyauchi E, Morita $\mathrm{H}$ and Tanabe S: Lactobacillus rhamnosus alleviates intestinal barrier dysfunction in part by increasing expression of zonula occludens- 1 and myosin light-chain kinase in vivo. J Dairy Sci 92: 2400-2408, 2009.

6. Isaacs K and Herfarth H: Role of probiotic therapy in IBD. Inflamm Bowel Dis 14: 1597-1605, 2008.

7. Sheil B, Shanahan F and O'Mahony L: Pobiotic effect on inflammatory bowel disease. J Nutr 137: 819-824, 2007. 
8. Steinman L: A brief history of Th17, the first major revision in the TH1/TH2 hypothesis of T cell-mediated tissue damage. Nat Med 13: 139-145, 2007.

9. Gaffen SL: An overview of IL-17 function and signaling. Cytokine 43: 402-407, 2008

10. Korn T, Bettelli E, Oukka M and Kuchroo VK: IL-17 and Th17 cells. Annu Rev Immunol 27: 485-517, 2009.

11. Kao CY, Chen Y and Thai P: IL-17 markedly up-regulates betadefensin-2 expression in human airway epithelium via JAK and NF-kappaB signaling pathways. J Immunol 173: 3482-3491, 2004

12. Xavier RJ and Podolsky DK: Unravelling the pathogenesis of inflammatory bowel disease. Nature 448: 427-434, 2007.

13. van den Berg WB and Miossec P: IL-17 as a future therapeutic target for rheumatoid arthritis. Nat Rev Rheumatol 5: 549-553, 2009.

14. Zhao Y, Yang J, Gao YD and Guo W: Th17 immunity in patients with allergic asthma. Int Arch Allergy Immunol 151: 297-307, 2009.

15. Ivanov II, Atarashi K, Manel N, et al: Induction of intestinal Th17 cells by segmented filamentous bacterium. Cell 139: 1-14, 2009.

16. Tanabe S, Kinuta Y and Saito Y: Bifidobacterium infantis suppresses proinflammatory interleukin-17 production in murine splenocytes and dextran sodium sulfate-induced intestinal inflammation. Int J Mol Med 22: 181-185, 2008.

17. Zhang Y, Palmer GH, Abbott JR, et al: CpG ODN 2006 and IL-12 are comparable for priming Th1 lymphocyte and $\mathrm{IgG}$ responses in cattle immunized with a rickettsial outer membrane protein in alum. Vaccine 21: 3307-3318, 2003.

18. Rozen S and Skaletsky H: Primer3 on the WWW for general users and for biologist programmers. Methods Mol Biol 132: 365-386, 2000

19. Luchansky JB, Tennant MC and Klaenhammer TR: Molecular cloning and deoxyribonucleic acid polymorphisms in Lactobacillus acidophilus and Lactobacillus gasseri. J Dairy Sci 74: 3293-3302, 1991.

20. Kimura A, Naka T and Kishimoto T: IL-6-dependent and -independent pathways in the development of interleukin 17-producing T helper cells. Proc Natl Acad Sci USA 104: 12099-12104, 2007.

21. Vilavsane A and Muruve DA: The innate immune response to DNA. Semin Immunol 21: 208-214, 2009.

22. Billiau A, Heremans H, Vandekerckhove F, et al: Enhancement of experimental allergic encephalomyelitis in mice by antibodies against IFN- $\gamma$. J Immunol 140: 1506-1510, 1998
23. Solt LA, Kumar N, Nuhant P, et al: Suppression of Th17 differentiation and autoimmunity by a synthetic ROR ligand. Nature 472 : 491-494, 2011.

24. Atarashi K, Nishimura J, Shima T, et al: ATP drives lamina propria Th17 cell differentiation. Nature 455: 808-812, 2008.

25. Gaboriau-Routhiau V, Rakotobe S, Lécuyer E, et al: The key role of segmented filamentous bacteria in the coordinated maturation of gut helper T cell responses. Immunity 31: 677-689, 2009.

26. Jyonouchi H, Geng L, Cushing-Ruby A and Monteiro IM: Aberrant responses to TLR agonists in pediatric IBD patients; the possible association with increased production of Th1/Th17 cytokines in response to candida, a luminal antigen. Pediatr Allergy Immunol 21: e747-e755, 2010

27. Zaba LC, Fuentes-Duculan J, Eungdamrong NJ, et al: Psoriasis is characterized by accumulation of immunostimulatory and Th1/ Th17 cell-polarizing myeloid dendritic cells. J Invest Dermatol 129: 79-88, 2009.

28. Boissier MC, Chiocchia G, Bessis N, et al: Biphasic effect of interferon- $\gamma$ in murine collagen-induced arthritis. Eur J Immunol 25: 1184-1190, 2005

29. Damsker JM, Hansen AM and Caspi RR: Th1 and Th17 cells: adversaries and collaborators. Ann NY Acad Sci 1183: 211-221, 2010.

30. Rachmilewitz D, Katakura K, Karmeili F, et al: Toll-like receptor 9 signaling mediates the anti-inflammatory effects of probiotics in murine experimental colitis. Gastroenterology 126: 520-528, 2004.

31. Wagner M, Poeck H, Jahrsdoerfer B, et al: IL-12p70-dependent Th1 induction by human B cells requires combined activation with CD40 ligand and CpG DNA. J Immunol 172: 954-963, 2004.

32. Hedin C, Whelan K and Lindsay JO: Evidence for the use of probiotics and prebiotics in inflammatory bowel disease: a review of clinical trials. Proc Nutr Soc 66: 307-315, 2007.

33. Pagnini C, Saeed R, Bamias G, et al: Probiotics promote gut health through stimulation of epithelial innate immunity. Proc Natl Acad Sci USA 107: 454-459, 2010.

34. Kekkonen RA,KajastoE,Miettinen M,et al:Probiotic Leuconostoc mesenteroides ssp. cremoris and Streptococcus thermophilus induce IL-12 and IFN- $\gamma$ production. World J Gastroenterol 14: $1192-1203,2008$ 